\title{
О.В. Нагель
}

\section{ФУНКЦИОНАЛЬНАЯ СПЕЦИФИКА ПРОИЗВОДНЫХ ИМЕН СИНКРЕТИЧНОЙ ЗОНЫ РУССКОГО СЛОВООБРАЗОВАНИЯ}

\begin{abstract}
В статье описьвается природа функциональной специифики русских производньх имен синкретичной семантики. Утверждается, что совмещение номинативного и прагматического аспектов в семантике синкретичного производного определяет его внешнесистемные отношения. На примере функционирования производных в позиции фокуса и топика анализируются сложный проиесс встраивания производньх в текст и настройка семантики как предтекста, так и последующего контекста на пропозициональные компоненты производного.

Ключевые слова: синкретичные производные, пропозиция, текстовое включение, позиция фокуса, позиция топика, актуализация пропозиционального содержания.
\end{abstract}

\section{Введение}

В работе представлено описание природы функциональной специфики производных одной из семантических зон русской словообразовательной системы, определяемой нами как зона синкретичной номинации [1-3]. Функциональная специфика производных анализируемой зоны в работе понимается как специфика внешнесистемных отношений производной единицы, которая реализована в тексте и ориентирована, посредством выстраивания данных отношений, на выполнение коммуникативной функции характеризации и оценки. Словообразовательные типы (СТ), используемые для образования исследуемых производных (см. весь список СТ в работе 4), характеризуются свойством семантического совмещения номинативного и прагматического аспектов, что является основанием их синкретичной природы. Например, мы считаем, что определение словообразовательного значения (С3) словообразовательного типа основа гл. + ун как «тот, кто характеризуется действием, названным производящей основой: говорун - тот, кто говорит» является недостаточно полным, так как не отражает ряд смыслов, которые появляются в результате именно словообразовательного акта. Например, Толковый словарь Ожегова [5] предлагает следующее толкование: Говор' ун, - $a$, м. (разг.). Человек, который любит много говорить. Данное толкование актуализирует оценочный смысл склонности к действию, названный производящей основой. Согласно словарному толкованию в результате словообразовательной операции появляется дополнительный смысл не только количественной (склонность к действию - говорению), но и качественной оценки (склонность к пустой болтовне): ГОВОРУ'Н, говоруна, муж. (разг.). Тот, кто склонен к многословию, к пустой болтовне [6]. Соответственно, в описание С3 предлагается включать значение отклонения от нормы данного признака: говорун тот, кто говорит, делает это часто, любит это делать, имеет к этому склонность и это может быть хорошо/плохо. Таким образом, производное, называя 
лицо по характерному для него действию, содержит в своей семантике модусный смысл рациональной оценки «больше нормы» и эмоциональную оценку «хорошо/плохо» $[3,4]$.

Семантический синкретизм рассматриваемых производных определяет специфику их текстового включения. Особенностью производного знака является то, что в нем оптимально согласуются когнитивные и коммуникативные задачи [7. С. 393]. С одной стороны, словообразование ориентировано на обеспечение познавательной деятельности человека, что обусловливает существование в языке определенного набора словообразовательных категорий и словообразовательных моделей, и определенным образом организованная словообразовательная система языка, таким образом, отражает актуальные когнитивные стратегии и смыслы, задействованные и рожденные в процессе взаимодействия человека и окружающего его мира. С другой стороны, производное слово, как результат словообразовательного акта ословливания происходящих в сознании человека когнитивных операций, рождается в дискурсивной среде и начинает жить и функционировать по законам дискурса: участвовать в создании условий для вариативного участия производной единицы в выражении топика и фокуса, в смене синтактико-семантических ролей в зависимости от коммуникативного задания. Семантическая структура производного слова объективирует особую пропозициональную структуру (см. далее Методологию), которая, в свою очередь, динамично встраивается в пропозициональную структуру высказывания и определяет особенности текстового вхождения производных.

В работе рассматривается функциональная активность анализируемых производных на материале Национального корпуса русского языка [8], исследуется вхождение расчлененной пропозициональной структуры производного имени в пропозициональную структуру высказывания в позиции фокуса и топика на материале оригинальных русскоязычных контекстов, которые содержат синкретичные производные. Кроме этого, выявляется типологическая специфика русского языка в использовании синкретичных производных для оценочной характеризации субъекта. На материале переводных контекстов с английского языка на русский анализируется выбор переводчиком синкретичного производного имени для передачи пропозитивного содержания, выраженного альтернативной языковой структурой (материалом для анализа выступают ресурсы параллельного подкорпуса Национального корпуса русского языка [8]. Обращение к межъязыковому сопоставлению мотивировано, прежде всего, тем, что типологическое сравнение является важным источником выявления специфики языковой номинации в языках, а перевод способен, с одной стороны, эксплицировать заложенные в семантике смыслы, с другой - установить уровень семантического тождества разноструктурных единиц $[9,10]$.

\section{Методология}

В данном исследовании изучение специфики формальных и содержательных признаков производного слова ведется согласно установкам функционально-когнитивного направления при исследовании композиционной семантики, которые заявляются как методологические принципы при изучении производного слова $[2,7,11,12]$. Основным вопросом функционально- 
когнитивного направления в исследовании композициональных аспектов языка является установление соотношения модели и ее реализации. При этом важно оговориться, что восприятие и участие в актах речи (сочетаемость с другими словами и в составе развернутых синтагматических последовательностей) определяется не только свойствами производного слова, но и коммуникативным заданием и когнитивными особенностями языкового субъекта.

\section{Пропозициональный подход}

В современной лингвистике язык определяется как когнитивный процесс в силу того, что он связан с осмыслением опыта человека и познанием мира. Любое языковое выражение рассматривается как обеспечивающее доступ к потенциально очень широкому спектру концептов, концептуальным комплексам или даже всей системе знания. [13. С. 4]. Считается, что языковые структуры разного порядка не существуют вне взаимосвязи с местом хранения и реального воспроизведения, т.е. понятие о языке как о монолитной системе заменяется идеей о том, что язык - это массивная организация разнородных конструкций, которые неразрывно связаны с контекстами и находятся в постоянном процессе структурной адаптации к использованию. Когнитивная семантика постулирует менталистическую теорию значения, идентифицируя его с концептуализацией, с ментальным опытом. В когнитивной лингвистике акцент ставится на изучение когнитивных процессов репрезентации внешнего и внутреннего мира мыслящего субъекта с помощью языковых знаков, а номинация понимается как соотнесенность языковых форм с их когнитивными аналогами или как процесс и результат объективированного осмысления действительности [7, 13-18]. По мнению Джерри Фодора, сами мысли и мыслительные процессы осуществляются в ментальном лексиконе, т.е. в символической системе, которая физически представлена в мозгу соответствующего организма. Природа мышления и организация человеческого сознания описывается посредством ментального языка, а именно, посредством пропозициональных отношений, реализующихся в предложениях следующего рода: ' $S$ верит, что $P$ '; ' $S$ надеется, что $P$ '; ' $S$ желает, что $P$ ' и т.д., где ' $S$ ' - субъект отношения, ' $P$ ' - любая предикация, а ' что $P$ ' относится к предположению, которое является объектом отношения. Если мы допускаем, что ' $A$ ' - это такие глаголы отношения, как 'верить', 'желать', 'надеяться', 'намереваться', ‘думать' и т.д., то пропозициональное отношение имеет следующую форму: $S A$, что $P$ [19. С. 17]. В данной философской традиции мысль является относительно достоверной лишь в том случае, если она выражена в системе репрезентаций, которые «означены» (закреплены лингвистической/семантической структурой и подчинены законам комбинаторного синтаксиса). В когнитивной лингвистике пропозициональные структуры также считаются одним из форматов знания, а наличие пропозициональной структуры обнаруживается в расчлененности объективировавшей ее конструкции. В иерархии способов формального выражения пропозиций первое место занимают структуры предложенческого типа, организуемые глаголом в спрягаемой форме с необходимыми именными распространителями. Все другие репрезентации являются вторичными и различаются степенью свернутости при представлении элементов пропозиции. Как отмечает Е.С. Кубрякова, «...именно способность производного слова объективировать пропозицио- 
нальные структуры и затем служить их простому угадыванию, способность служить такой единицей номинации, которая удобна для упаковки информации и использования ее в речевой деятельности, и характеризует ПС как особую когнитивно-дискурсивную структуру [7. С. 394].

Пропозициональный подход в дериватологии явился логическим продолжением изучения словообразования на синтаксической основе, при котором исследовался изоморфизм словообразовательных и синтаксических единиц. В качестве смысловой базы деривационных процессов рассматривалась синтагматически организованная структура, обычно отождествляемая с предложением или высказыванием. М.Н. Янценецкая указывала на то, что в данном аспекте точнее было бы говорить не о синтаксической структуре, а о ее пропозитивном содержании. Автор отмечает, что «производное слово должно соотноситься не с тем или иным конкретным предложением или синтаксическим оборотом, а с глубинной пропозицией, которая, в свою очередь, может получить синтаксическое, морфологическое или лексическое выражение» [12. С. 9].

В семантике производного слова пропозиция, как утверждает Л.А. Араева, представлена в свернутом виде с реализацией минимальной либо максимальной, многоместной структурно-логической схемы. Абстрактный характер пропозиции делает возможным репрезентацию ее несколькими тематическими объединениями производных. Развернутая, многоместная пропозиция реализуется комплексом мотивирующих единиц, выстроенных в определенном порядке сообразно той функции, которую выполняет в пропозиции производное слово, что обусловливает видение одной и той же пропозиции каждый раз в новом ракурсе [11. С. 79]. Изучение расчлененной семантической структуры ПС посредством пропозиционального подхода позволяет выявить те составляющие человеческой когниции, объединение которых и приводит к целостной картине познаваемого мира. Наблюдается взаимодействие языка и человека во всем его многообразии. Язык позволяет человеку выразить то, что он познает, а человек, в свою очередь, каждый раз насыщает языковую модель новым знанием, новым потенциалом.

\section{Пропозициональные модели семантической организации синкретич- ных производных имен}

Производные синкретичных СТ рождаются как ответ на активизацию разных структур сознания. Человек категоризирует объект действительности на основе определенных признаков, соотносит его с нормативной шкалой, реагирует на нормативное отклонение. Данные структуры сознания объединены и объективированы в сжатой форме синкретичного производного. Результатом объективации является сложная организация С3 синкретичного производного, которая представлена полипропозициональной структурой и оформлена модальными планами. Организация мотивирующего суждения русских производных синкретичных СТ осуществляется по двум семантическим моделям, отличающимся природой оценочного потенциала и способом его формирования.

В состав Модели (1) входят производные, образованные от оценочнонейтральных мотивирующих (например, говорить - говорун), в состав Модели (2) входят производные, образованные от оценочных мотивирующих (на- 
пример, шалить - шалун). Семантика мотивирующей единицы определяет объективное содержание предикатного компонента первой пропозиции (например, работать, говорить, иметь бороду, волосы и т.д.). В процессе словообразовательного акта вторая зависимая пропозиция, фиксирующая отклонения от нормы, включает в себя модальную рамку рациональной оценки (M2) (например, работать много, говорить много, иметь большую бороду, иметь много волос). Рациональная оценка в рамках моделей акцентирует как количественное (M2ql), так и качественное отклонение (M2qn) (например, рифмач - писать, используя рифмы и делать это плохо; политикан - заниматься политикой и делать это плохо). Факт отклонения от нормы порождает субъективную эмоциональную оценку (М3) как реакцию на обозначенное отклонение (например, быть политиканом - плохо (неодобрение)).

Основной спецификой Модели (1) является то, что вся оценочная семантика порождена действием словообразовательного механизма (взаимодействие суффикса и основы). Схематично совокупность смыслов в рамках первой модели можно представить следующим образом: (S2) полагает, что (S1) характеризуется $(\mathrm{P})$, при этом $\mathrm{P}=\mathrm{N}(\mathrm{M} 1=0)$, но $\mathrm{S} 1$ характеризуется $\mathrm{P}$ всегда, часто, имеет склонность, любит и, следовательно, P' > N (M2qn) и делает это хорошо/плохо(M2ql) => и это вызывает реакцию (M3) (ср. пропозициональные отношения по Фодору, представленные выше). Например, когнитивное основание словообразовательного значения производного работяга может быть проинтерпретировано следующим образом: Некто (S2) полагает, что $(\mathrm{S} 1)$ работает $(\mathrm{P})(\mathrm{M} 1=0)$ и работает много $\left(\mathrm{P}^{\prime}>\mathrm{N}\right)(\mathrm{M} 2 \mathrm{qn})$, и работает хорошо (M2q1), что вызывает определенные эмоции (M3).

Синкретичные производные в рамках Модели (2) представляются более эмоционально-оценочными. Наследуемая оценочная семантика от мотивирующей единицы накладывается на оценку, рожденную в процессе словообразовательного акта, таким образом образуется более интенсивная оценочная семантика. В результате и основная (что (S1) лжет (P)), и зависимая (лжет много) осложнены модальностью оценки. Но оценочность, заложенная в семантике мотивирующей единицы, не находится в функциональном фокусе. Она представляет некую пресуппозицию, некий оценочный фон для создания оценочного наименования. Данное содержание составляет наследуемый модус рациональной оценки (M1). При этом мотивирующая единица несет в себе чаще всего качественную оценку (M1ql) (например, лгать, болтать, хвастать). Рациональная оценка (M2), выражающая количественное отклонение (M2qn) (например, лгун - тот, кто много лжёт), определяет содержание эмотивного модуса (М3) (например, лгать плохо, но допускается (см. далее пример 1), а быть лгуном - осуждается) и порождается в процессе деривационного акта. Схематично данная модель выглядит следующим образом: (S2) полагает, что S1 характеризуется Р, при этом данное действие не соответствует норме $(\mathrm{P}=/ /=\mathrm{N}(\mathrm{M} 1 \mathrm{ql}))$, и $\mathrm{S} 1$ характеризуется Р всегда, часто, имеет склонность, любит и, следовательно, P' > N (M2qn) => и это вызывает реакцию (М3). Например: кривляка - Некто (S2) полагает, что (S1) кривляется (P), при этом действие кривляться не соответствует норме $(\mathrm{P}=/ /=\mathrm{N}$ (M1ql)), и (S1) кривляется (P) всегда, часто, имеет склонность, любит и, следовательно, P’>N (M2qn) => и это вызывает реакцию (M3). Таким образом, в 
рамках второй модели в словообразовательном процессе участвуют оценочные мотивирующие, но коммуникативно значимая оценка рождается также лишь в самом словообразовательном акте и именно она определяет содержание эмотивного модуса, т.е. реакцию говорящего на оцениваемый признак.

\section{Функциональная активность синкретичных производных имен}

В функциональном плане синкретичная зона является системно организованной зоной. В представленных Модели (1) и Модели (2) можно выделить производные, которые имеют от 1 до 10 вхождений в корпусе (например, орун, наивняк, стрекотуха, голован), и производные, которые характеризуются диапазоном частотности от 300 вхождений и более (например, певеu, толстяк, игрок, бродяга). Представлять более конкретные цифры частотности вхождений не целесообразно, так как Национальный корпус русского языка является информационно-справочной системой, которая постоянно пополняется как за счет современных источников, так и источников русского наследия [8]. Разнообразная функциональная частотность производных синкретичной зоны свидетельствует о её устойчивости. Системная устойчивость в функциональном плане также подкрепляется единообразием текстового функционирования русских синкретичных производных вне зависимости от их частотности.

\section{Характеристика текстового включения синкретичного производного имени}

Двойственная ориентация при выражении смысла в рамках производного диктует свои правила текстового функционирования. В тексте в синкретичном производном в зависимости от коммуникативного задания актуализируется либо объективное (субъект, предикат, модус объективной оценки), либо субъективное содержание (модус субъективной оценки). Коммуникативный запрос также определяет использование соответствующих актуализаторов, вытягивающих/активизирующих имплицитные смыслы синкретичного имени.

\section{Синкретичное производное имя в коммуникативном развертывании текста}

Синкретичные имена в составе высказывания выступают как определенные «информационные структуры», коррелирующие с предполагаемыми ментальными состояниями говорящих и слушающих. Синкретичное производное в коммуникативном развертывании текста принимает участие в осуществлении прагматических связей текста, проявляя способность изменять направление сообщения. Важно подчеркнуть, что актуализация пропозитивного и оценочного содержания семантической структуры синкретичных производных происходит в тексте как в позиции фокуса/ремы, когда у говорящего уже есть предпосылочное знание о ситуации, и обозначение участника синкретичным именем позволяет оценить его действия и выразить субъективное отношение к нему, так и топика/темы, когда задается содержание и тон последующего повествования. Данный факт подчеркивает динамичность и гибкость семантической структуры синкретичных производных. Важно отметить, что в контексте функционирования синкретичного имени мы определяем позицию фокуса и топика в зависимости от актуализации пропозитивного содержания до или после синкретичного производного соответственно. 
В терминах семантического синтаксиса топик (или тема) представляет часть предложения, передающую низшую степень коммуникативного динамизма [20. С. 376], он относится к той информации, которая уже присутствует в лингвистическом или ситуативном контексте. В терминах линейного распределения информации топик относится к синтаксическим процессам, которые удерживают языковую единицу в левой позиции, или к синтаксическим процессам, которые заключаются в том, чтобы перенести определенный компонент в левую позицию. Позиция топика исключает элементы, которые несут предикацию и которым требуются элементы, выполняющие референтную функцию. Таким образом, синтаксическая позиция топика схожа с синтаксической позицией подлежащего. Как отмечал У. Чейф, «топик является чем-то вроде подлежащего... возможно, возник из подлежащего, которое выбрано слишком поспешно и не очень гладко входит в последующее предложение...» [21. С. 311].

Фокус (рема) представляет ту часть предложения, которая передает высшую степень коммуникативного динамизма [20. С. 376] и относится к той информации, которая не присутствовала (или присутствовала лишь частично) в лингвистическом или ситуативном контексте. В рамках синтаксической структуры фокус относится к синтаксическим процессам, которые удерживают или переносят компоненты высказывания в правую позицию предложения.

Таким образом, возвращаясь к прагматическому пониманию организации высказывания, отметим, что компоненты, находящиеся в левой части предложения, принадлежат той части высказывания, которая является центром внимания Говорящего и Слушающего (center of attention), а компоненты, характеризующиеся положением справа, организуют вершины выделения (peaks of prominence). Особенностью языковой коммуникации, в которую не включены эмфатические элементы, является организация потока информации в высказывании согласно стратегии привлечения внимания в первую очередь к элементам уже известным, а затем выделение чего-либо нового. Синкретичные производные включаются в текст с пропозитивным и оценочным предназначением, т.е. активированными компонентами его пропозитивной структуры в позиции предиката/ремы/фокуса высказывания. Говорящий, имея определенное предпосылочное знание внешнего текста о ситуации, обозначает участника синкретичным именем и тем самым оценивает его действия, сообщает о своем отношении к данному событию. В высказывании актуализируется пропозитивный смысл, «между смыслом номинации и значением предиката устанавливаются отношения причинности» [22. С. 330].

Рассмотрим более подробно вхождение синкретичных производных в текст как в позиции фокуса, так и в позиции топика.

\section{Коммуникативная позиция фокуса/ремы}

Коммуникативная позиция фокуса/ремы актуализирует предикативные и оценочные компоненты пропозитивной семантики синкретичного имени. При использовании синкретичного производного происходит не только компрессия предшествующего контекста, но и вводится дополнительная пропозиция оценки. Рассмотрим характерный пример включения синкретичного производного в информационную структуру высказывания. 


\section{Пример (1)}

Mbl слишком привыкли смотреть на понятие ложь с лищемернофарисейской точки зрения прописной морали. Нет, ложь, выдумка имеют такие же права гражданства, как и добродетельная правда. Одно только условие: лги талантливо. Кмоо врет талантливо - художник, кто врет без-

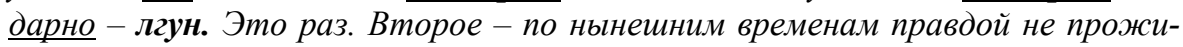
вешь. - Но, мильй, ты смешиваешь разные вещии [А.С. Серафимович. Заметки обо всем (1902-1903)].

В примере (1) представлено функционирование синкретичного имени лгун. Данное производное имя по своей пропозитивной структуре относится к Модели (2), так как в словообразовательном механизме участвует оценочная производящая единица лгать (ложь - преступление против истины [23]. Как мы уже отмечали, и основная, и зависимая пропозиции в данном случае осложнены модальностью оценки. Она представляет некую пресуппозицию, некий оценочный фон для создания оценочного наименования. Данное содержание составляет наследуемый модус рациональной оценки (M1) и обобщенное содержание эмотивного модуса (M3), которое выводится из семантики производящей единицы. Но оценочность, заложенная в семантике мотивирующей единицы, не находится в функциональном фокусе, более того, в данном конкретном примере автор изменяет семантику, т.е., будучи обозначенным синкретичным производным, человек оценивается не только по тому, что он лжет, а по тому, как он это делает. И именно последнее вызывает эмоции говорящего. Как отмечалось выше, семантика словообразовательного типа основа глагола + - ун, указывает на то, что он это делает «часто», «постоянно», «всегда»-лгун, а контекст определяет знак эмотивного модуса. До появления данного имени в контексте функционируют такие единицы, как ложь, выдумка, лги, кто врет, которые определяют тему данного высказывания, и использование производного имени лгун не только вбирает в себя содержание данных единиц, но и закрепляет оценку говорящего за обсуждаемым явлением, причем эмотивный модус синкретичного имени лгун актуализируется не за счет семантики производящей единицы, так как в данном

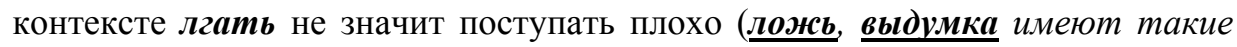
же права гражданства, лги талантливо. кмо врет талантливо - худож$н и \kappa)$. Эмотивный модус актуализируется семантикой наречия бездарно (только тот, кто врет бездарно может называться лгуном).

Аналогичное функционирование возможно наблюдать и для синкретичных производных, относящихся к Модели (1), основу которой составляют производные, образованные от нейтральных в оценочном плане единиц $(\mathrm{M} 1=0)$. Рациональная и эмоциональная оценки рождаются в словообразовательном акте. В рамках данной модели в составе производного мотивирующая единица является единицей нейтрального уровня. Она несет объективное содержание предикативного компонента первой пропозиции: певец - тот, кто nоёт; бородач - тот, у кого борода. В процессе словообразовательного акта вторая зависимая пропозиция составляет модальную рамку рациональной оценки (М2): певец «тот, кто поёт (1), но делает это больше нормы (2)»; бородач «тот, у кого есть борода (1), но она не соответствует норме (2)»; гово- 
рун «тот, кто говорит, но делает это больше/несоответствие нормы (2). Рациональная оценка в рамках данной модели акцентирует как количественное (M2q1), так и качественное отклонение (M2qn): говорун - тот, кто много говоpum, но то, как и что он говорит, не соответствует норме. Факт отклонения от нормы порождает субъективную эмоциональную оценку (M3) как реакцию на обозначенное отклонение. Рассмотрим контекст с синкретичным производным говорун:

\section{Пример (2)}

Надо... развязней быть. Поговорить... - Ты уж один раз поговорил... Говорун. - Конечно. А то сидим, как ариин проглотили. Надо, чтоб мьл людям не в тягость были... [Василий Шукшин. Печки-лавочки (1970-1972)].

В анализируемом контексте синкретичному имени говорун предшествуют глаголы поговорить, актуализирующие предикативный компонент (mom, кmo говорит) пропозитивного содержания. Оценочный модус превышения нормы актуализирован фразой $\underline{T b l}$ уж один раз поговорил, которая подчеркивает, что действие уже совершалось до момента речи.

Семантическая открытость синкретичного имени при вхождении в текст реализуется в гибкости формального оформления предтекста для синкретичного имени. Синкретичному производному имени зачастую предшествуют мотивирующие единицы с производящим корнем (петь - певец, лгать - лгун, бородатьй - бородач, говорить - говорун и т.д.). В такого рода примерах происходит своеобразная семантическая преднастройка (семантический прайминг) для введения производного имени в текст и актуализация его расчлененной формы и содержания. Кроме этого, в предтексте возможно использование слов, которые являются семантически синонимичными корню синкретичного имени, но морфонологически с ним не совпадают. Например, толковать - говорун:

\section{Пример (3)}

Он продолжал бредить - все толковал о весне и о какой-то девушке. Ну, говорун! - не утерпел Умрихин [Михаил Бубеннов. Белая береза, части 12 (1942-1952)].

Оценочный модус в примере (3) актуализируется семантикой слова бредить (говорить бессвязно, непонятно) в предтексте и восклицательной конструкцией $(H y \ldots !)$.

Типологические особенности использования синкретичных производных в позиции фокуса/ремы

При рассмотрении природы словообразовательных процессов и способов идентификации производных слов исследователи склонны говорить о типологической универсальности словообразовательных процессов. И действительно, многие функции производных единиц являются универсальными для языков с развитой деривационной системой, но частотность и выраженность данных функций в разных языках может быть различной. Использование производного как инструмента компрессии предыдущего контекста возмож- 
но и в английском языке, как с повторением морфологических компонентов (lie (лгать) - liar (лжец), fat (толстый) - fatty (толстяк), singing (пение) song (песня) - singer (певеu)), так и с альтернативным оформлением семантического наполнения very fond of his meat, I mind; he was a hearty (очень любил мясо, обильную еду) - eater (едок).

\section{Пример (4)}

en Lie upon lie he has given us; he has been proven a chronic liar; are you to believe this last and fearfully impossible lie? [Jack London. A Daughter of the Snows (1902)].

ги Он громоздит одну ложь на другую. Доказано, что он бессовестньий люец. Неужели вы поверите этому последнему чудовищному вымыслу? [Джек Лондон. Дочь снегов (Н. Давыдова, Н. Рачинская, 1927)].

Утверждение о том, что для русского языка использование синкретичных производных в данной функции является более распространенным, доказывается примерами из параллельного корпуса, где непроизводные единицы, используемые в английских контекстах, переводятся на русский именно синкретичными производными: eat all the cakes - He is too fat - толстяк, A paunchy man - The man vs. пузатый мужчина - Пузан; , I am not proud, since pride is destruction vs. я не возгордился, потому что гордеи скоро погибает, It ish my fat - yaw - he say I bees pad mit fat - Не - толстяк, The таn - пузан, ride is destruction - гордец, Big Olaf-Толстяк Олаф.

\section{Пример (5)}

en "Mind Bilbo doesn't eat all the cakes!" they called. "He is too fat to get through key-holes yet!" [J. R. R. Tolkien. The Hobbit (1937)].

rи - Следите, чтобы Бильбо не съел все кексы! - кричали другие. - Такой толстяк не пролезет в замочную скважину! [Дж. Р. Р. Толкин. Хоббит (Н. Рахманова, 1976)].

Наиболее ярко различие между русским и английским языком в данном аспекте наблюдается в контекстах, где в английском предложении предикация и оценка, выраженные в предтексте, не получают дальнейшей актуализации (It ish my fat -yaw - he say I bees pad mit fat"! he explained to Ben, а в русском варианте переводчик выбирает синкретичное производное имя для компрессии предикации и конкретизации оценочного контекста: объяснил Бону добродушный толстяк.

\section{Пример (6)}

en It ish my fat-yaw - he say I bees pad mit fat"! he explained to Ben. So a vote was passed unanimously in favor of allowing the now popular Voost to join the party, if his parents would consent". [Mary Mapes Dodge. Hans Brinker or the Silver Skates (1865)].

ги - Это мой жир, йа, он говорит, я ношу подушки из жира! - объяснил Бону добродушный толстяк. Острота Вооста имела такой успех, что все единогласно решили принять его в компанию, если только его родители со- 
гласятся. [Мэри Мейпс Додж. Серебряные коньки (М.И. КлягинаКондратьева, 1941)].

\section{Коммуникативная позиция топика/темы}

Использование синкретичного производного в позиции топика/темы задает содержание и тон последующего повествования. В данной позиции предикативный компонент может быть актуализирован мотивирующим словом (например, болтун - болтает, бородач - выросла борода).

\section{Пример (7)}

Болтун болтает, другой будет болтать другое, а мне все равно, не сегодня завтра умирать. [М.П. Аризыбашев. Санин (1902)].

Пример (8)

Он не болтун, он деятель, а болтает он, может, так, для сокрытия всего остального. [Ю.О. Домбровский. Факультет ненужных вещей, часть 4 (1978)].

Интересной отличительной чертой актуализации пропозитивного содержания синкретичного имени в контекстах с последующей разверткой предикативного содержания является использование перед синкретичным именем дополнительных актуализаторов, активирующих либо субъектный (езнакомый бородач; дряхльий болтун; иностранеи-богач), либо эмотивный (неприятный толстяк) компоненты.

\section{Пример (9)}

А в крайнем случае (чего я, действительно, боюсь?) отразился бы в нем незнакомый бородач, - здорово она у меня выросла, эта самая борода, - $и$ за такой короткий срок, -я другой, совсем другой, -я не вижу себя [В.В. Набоков. Отчаяние (1932)].

Предикативное содержание может также получить развертку за счет использования синонимов (не болтун - не скажу, болтун - разговорился), развернутых определительных конструкций (богач - купил бы весь ее товар, $u$ переплатил, и заказал бы еще и еще видовых открыток, путеводителей всяких; толстяк - похожий на борова).

\section{Пример (10)}

Не беспокойтесь, я всё знаю, от него же самого, и я не болтун; никому не скажу. [Ф. М. Достоевский. Преступление и наказание (1866)].

Пример (11)

Пока я раздумывал, подойти к нему или нет (полагая, что со вчерашнего вечера он успел забыть и лиио мое, и фамилию), этот дряхлый болтун, боявшийся утаить крупииу зерна из закромов опьтта, разговорился с незнакомой ему пожилой дамой, падкой, очевидно, до всякой чужой души. [В.В. Набоков. Соглядатай (1930)]. 
Пример (12)

Мне кажется, ей представлялся иностранеи-богач из Адлона, который купил бы весь ее товар, и переплатил, и заказал бы еще и еще видовых открыток, путеводителей всяких [В.В. Набоков. Благость (1924)].

Пример (13)

Семья Кюияам состояла из пяти человек: Альбина Кюиам - мать, пожилая полная женщина с тяжельм, придавливающим взором черных глаз и со следами былой красоты на старом лище, ее две дочери - Леля и Тая, маленький сынишка Лели и старик Кюияам, неприятный толстяк, похожий на борова.

Типологические различия использования синкретичных производных в позиции топика/темь

Для английского языка также возможно, но не характерно использование производного имени в позиции топика, т.е. в позиции, предшествующей развертке пропозитивного содержания за счет использования мотивирующей единицы (a talker - told; the reader - to finish reading, swimmer - I swim fairly well-swim ashore)

Пример (14)

en Neither did I, to be sure, he was so loose a talker; yet in this case I believe he was really right and that nobody had told the situation of the island [Robert Louis Stevenson. Treasure Island (1883)].

ги Я тоже тогда не поверил, потому что он действительно был великий болтун; а теперь я думаю, что тогда он говорил правду и что команде было известно и без нас, где находится остров [Роберт Луис Стивенсон. Остров сокровищ (Н. Чуковский, 1935)].

Пример (15)

en The abbot stopped in the corridor to wait for the reader to finish reading. [Walter M. Miller, Jr.. A Canticle For Leibowitz (1960)].

ги Аббат остановился в коридоре, ожидая, пока чтец окончит сообщение. [Уолтер Миллер. Страсти по Лейбовииу (С. Борисов, 1999)].

Пример (16)

en He was an excellent swimmer and could swim ashore, no doubt - whatever the distance. [Theodore Dreiser. An American Tragedy, book I-II (1925)].

ги Он превосходный пловец, он, без сомнения, доплыл бы до берега, каково бы ни было расстояние [Теодор Драйзер. Американская трагедия (части 1-2) (Нора Галь, 3. Вершинина, 1948)].

Пример (17)

en But when she was still alive out there in the water - how about that? You're a pretty good swimmer, aren't you? "Yes, sir, I swim fairly well [Theodore Dreiser. An American Tragedy, book III (1925)].

ги Ну, а пока она была еще жива и держалась на воде, как было дело? Вbl ведь отличный пловец, так? - Да, сэр, я плаваю недурно [Теодор Драйзер. Американская трагедия, часть 3 (Нора Галь, 3. Вериинина, 1948)].

Раскрытие пропозитивного содержания также происходит посредством использования развернутых объяснительных конструкций, дефиниций в рамках одного предложения: intriguer - dint of fawning on various Extremist offi- 
cials had obtained the post, profligate - easily attached to his person and faction, not only all who had reason to dread the resentment of Richard for criminal proceedings during his absence.

Пример (18)

en An old intriguer who by dint of fawning on various Extremist officials had obtained the post of Scenic Director, suddenly pointed a vibrating finger at the King, but being afflicted with a bad stammer could not utter the words of indignant recognition which were making his dentures clack [Vladimir Nabokov. Pale Fire (1962)].

ги Старый интриган, который подслуживанием к разным экстремистским чиновникам добился режиссерской должности, внезапно указал трясущчимся пальцем на короля, но, страдая сильным заиканием, не мог произнести слов возмущенного опознания, которое заставляло щелкать его искусственные челюсти [Владимир Набоков. Бледный огонь (Вера Набокова, 1983)].

Пример (19)

en His own character being light profligate and perfidious, John easily attached to his person and faction, not only all who had reason to dread the resentment of Richard for criminal proceedings during his absence, but also the numerous class of "lawless resolutes, " whom the crusades had turnedback on their country, accomplished in the vices of the East, impoverished in substance, and hardened in character, and who placed their hopes of harvest in civil commotion [Walter Scott. Ivanhoe (1819)].

ги Ловкий интриган и кутила, прини Джон без труда привлек на свою сторону не только тех, кто имел причины опасаться гнева Ричарда за преступления, совершенные во время его отсутствия, но и многочисленную ватагу "отчаянных беззаконников" - бывиих участников крестовых походов. Эти люди вернулись на родину, обогатившись всеми пороками Востока, но обнищав, и теперь только и ждали междоусобной войны, чтобы поправить свои дела [Вальтер Скотт. Айвенго (Е. Бекетова, 1890-1902)].

Специфику русского языка, отдающего предпочтение синкретичному имени для характеризующей номинации при переводе возможно наблюдать и в топикализированной позиции производного. Необходимо отметить, что в данных примерах переводчик выбирает эквивалентом синкретичное производное имя для развернутых, ярких и образных характеристик субъекта, тем самым подтверждая семантическую насыщенность и высокий оценочный потенциал русского синкретичного имени (scheming - интриган; have a tonguе - болтун; an old bag of wind - болтун; a man of property - богач).

Пример (20)

en Simley knows exactly the sort of man Banner is - an opportunist, a selfish, scheming, conniving lawyer who keeps trying to get my husband to rely on him more and more in matters of business as well as in matters of law [Erle Stanley Gardner. The Case of the Daring Divorcee (1964)].

rи Симли хорошо знает, что за человек Баннер: оппортунист, самонадеянный интриган, хитрый адвокат, который пытается заставить моего 
мужа во всем полагаться на него при решении деловых и юридических вопросов [Эрл Стэнли Гарднер. Дело смелой разведенки (М. Кудрявцева, 1990)].

Пример (21)

en I have a tongue, you know, and it used to wag [Graham Greene. The Power and the Glory (1940)].

ги Я, знаете ли, болтун, вечно трепал языком [Грэм Грин. Сила и слава (Н. Волжина, 1970-1980)].

Пример (22)

en Archie thought, and frequently said, that Grandpa was an old bag of wind and Archie had no intention of letting him insult Miss Melanie's husband, even if Miss Melanie's husband was talking like a fool [Margaret Mitchell. Gone with the Wind, Part 2 (1936)].

ги Арчи считал - да частенько и говорил, - что дедушка Мерриуэзер пустой болтун, но Арчи не намерен был сидеть и слушать, как он оскорбляет супруга мисс Мелани, даже если супруг мисс Мелани несет какую-то чушь [Маргарет Митчелл. Унесённые ветром, часть 2 (Т. Кудрявцева, 1982)].

\section{Пример (23)}

en If that young Soames were such a man of property, he would never miss a thousand a year or so; and under his great white moustache old Jolyon grimly smiled [John Galsworthy. The Man of Property (1906)].

ги Если этот Сомс действительно такой богач, он не заметит отсутствия тысячи фунтов в год, и под седыми усами старого Джолиона появилась хмурая ульюбка [Джон Голсуорси. Собственник (Н. Волжина, 1946)].

Необходимо отметить, что в переводе на русский язык зачастую добавляется актуализатор пропозитивного содержания, например: have a tongue болтун, вечно(М2) трепал языком(М3) (Пример 21); an old bag of wind пустой (М2, М3) болтун (Пример 22).

Интересны случаи актуализации предикативного содержания производного имени как до, так и после него. Например, в следующем контексте (Пример 24) синкретичное производное имя «толстяк» находится в коммуникативном центре высказывания с предшествующим растолстел $(P, M 2)$ и последующим Все загривок в барах нагуливаешь... При этом следующая за синкретичным именем развертка актуализирует как предикативный (Р), так и модусные (М2, М3) смыслы.

\section{Пример (24)}

- Я так и знал, что это ты, - сказал Рэдрик, оглядывая Нунана быстрыми зеленоватыми глазами. - У-y, растолстел(Р,M2), толстяк! Все загривок в барах нагуливаешь(М2, М3)... Эге! Да вы тут, я вижу, весело время проводите! Гута, старушка, сделай мне поричю, надо догонять... [А.Н. Стругаџкий, Б.Н. Стругачкий. Пикник на обочине (1971)].

Переводные контексты (25-28), в которых синкретичное производное имя используются переводчиками как эквивалентная единица для различных предикативных единиц: shot - cmpелок, he - толстяк, He is too fat - mолстяк, также ярко демонстрируют динамику вхождения синкретичного имени 
в текст, проявляющуюся в способности производного имени сжать предшествующее характеризующее суждение, переструктурировать его фокус и стимулировать его разворот, акцентируя именно оценочный компонент суждения (пострелять $(P)$ грачей $\rightarrow$ прекрасньй(M2) стрелок $\rightarrow$ он превосходно(М3) стреляет (P); пристрелить(Р) меня $\rightarrow$ меткий (M2) стрелок $\rightarrow$ я научил тебя стрелять(P, M2, М3); Комбинезон на его животе оттопыривался так сильно (P, M2) $\rightarrow$ толстяк $\rightarrow$ проглотил баскетбольный мяч(M2, M3), съел все кексы(M2, М3) $\rightarrow$ толстяк $\rightarrow$ не пролезет в замочную скважи$\mathrm{Hy}(\mathrm{M2}, \mathrm{M3})$ )

\section{Пример (25)}

en 'Why, your friend and I, ' replied the host, 'are going out rook-shooting before breakfast.' He's a very good shot, ain't he? ' 'I've heard him say he's a capital one, ' replied Mr. Pickwick, 'but I never saw him aim at anything.' [Charles Dickens The Posthumous Papers of the Pickwick Club (1836-1837)].

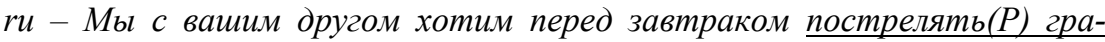
чей,- ответил хозяин.-- Он, кажется, прекрасный(М2) стрелок. - Я сльхал от него, что он превосходно(М3) стреляет $(P)$, - отозвался мистер Пиквик , - но никогда еще не видал [Чарльз Диккенс. Посмертные записки Пиквикского клуба (А.В. Кривиова, Е.Л. Ланн, 1933)].

Пример (26)

en Or you can shoot me. You're a good shot now. I taught you to shoot didn't I?" [Ernest Hemingway. The Snows of Kilimanjaro (1936)].

ги Или можешь пристрелить(P) меня. Ты теперь меткий (M2) стрелок. Ведь я научил тебя стрелять (P, M2, М3)? [Эрнест Хемингуэй. Снега Килиманджаро (Н. Волжина, 1956)].

Пример (27)

en The curve of his belly pushed his faded blue overall out to a point where Harold half suspected he had swallowed a basketball [Stephen King. The Lawnmower Man (1975)].

ги Комбинезон на его животе оттопыривался так сильно (P,M2), что Гарольд подумал, что толстяк, может быть, проглотил баскетбольный мяч (М2, М3). [Стивен Кинг. Газонокосильщик (А. Мясников, 1993)].

Пример (28)

en "Mind Bilbo doesn't eat all the cakes!" they called. "He is too fat to get through key-holes yet!" [J. R. R. Tolkien. The Hobbit (1937)]

rи - Следите, чтобы Бильбо не съел все кексы(М2,M3)! - кричали другие.- Такой толстяк не пролезет в замочную скважину (M2,M3)! [Дж. Р.Р. Толкин. Хоббит (Н. Рахманова, 1976)].

\section{Заключение}

Таким образом, анализ функциональной специфики русских синкретичных имен показал, что синкретичная природа пропозитивного содержания данных производных определяет законы их текстового включения. При использовании синкретичного производного в тексте происходит сложный процесс встраивания его пропозиционального содержания в пропозицию предложения. Данный процесс проявляется в настройке семантики как предтекста (языковые единицы до производного имени), так и последующего кон- 
текста (языковые единицы после производного имени) на пропозициональные компоненты производного (S, P, M1, M2, M3). Мы отмечаем, что такого рода коммуникативная стратегия характерна и для английского языка, но в силу того, что английский язык не имеет ярко выраженной зоны семантического словообразования, ориентированной на одновременное обслуживание как объективного, так и прагматического содержания, данную функцию выполняют другие языковые единицы, которые в русском переводе получают эквивалент в виде синкретичного производного имени. Анализ переводных контекстов позволяет использовать перевод как инструмент выявления специфики русской деривационной системы, заключающейся в функционально активной синкретичной зоне суффиксального именного словообразования.

\section{Лumepamypa}

1. Резанова 3.И. Функциональный аспект словообразования: Русское производное имя. Томск, 1996. $218 \mathrm{c}$.

2. Резанова 3.И. Именная деминутивная деривация в механизмах выражения оценки // Картины русского мира: Аксиология в языке и тексте. Томск, 2005. С.194-231.

3. Нагель О.В. Русские именные словообразовательные типы синкретичной семантики (функционально-когнитивный аспект): дис. ... канд. филол. наук. Томск, 2005. 224 с.

4. Нагель O.B. Семантика производного имени как активатор метаязыкового сознания носителя русского языка // Вестн. Том. гос. ун-та. Филология. 2014. № 2 (28). С. 63-71.

5. Толковый словарь Ожегова. URL: http://slovarius.com/page/govorun.php (дата обращения: 15.03.2016).

6. Толковый словарь русского языка / под ред. Д.Н. Ушакова. URL: http:// slovariya. ru/ rus/sa/govorun (дата обращения: 15.03.2016).

7. Кубрякова E.C. Язык и знание: На пути получения знаний о языке: Части речи с когнитивной точки зрения. Роль языка в познании мира. М.: Языки славянской культуры, 2004. 560 с.

8. Национальный корпус русского языка / Институт русского языка им. В.В. Виноградова PAH. M., 2015. URL: http://www.ruscorpora.ru (дата обращения: 15.03.2016).

9. Нагель О.В. Деривационная специфика наименований лица в славянских языках (на материале параллельного подкорпуса НКРЯ) // Русин. 2015. №3 (41). С. 226-240.

10. Резанова 3.И., Шиляев К.С. Национальный корпус русского языка в обучении особенностям использования русских диминутивов // Международный журнал прикладных и фундаментальных исследований. 2015. № 5. С. 634-63.

11. Араева Л.А. Словообразовательный тип. M.: URSS, 2009. 268 с.

12. Янщенеикая М.Н. Пропозициональный аспект словообразования (обзор работ сибирских дериватологов) // Вестн. Том. Гос. ун-та. Филология. 2014. № 1 (27). С. 167-192.

13. Langacker R. Foundations of Cognitive Grammar. Stanford 5-7, 1991. 589 p.

14. Chomsky N. Linguistics and cognitive science: problems and mysteries // A. Kasher (ed.), The Chomskyan Turn: Generative linguistics, philosophy, mathematics, and psychology. 1991. Oxford: Blackwell.

15. Croft W., Cruse D.A. Cognitive linguistics. Cambridge: Cambridge University Press. 2004.

16. Talmy $L$. Towards a cognitive semantics. 2000. Vol. 1-2. The MIT Press.

17. Демьянков B.3. Когнитивная лингвистика как разновидность интерпретирующего подхода // Вопр. языкознания. 1994. № 4. С. 17-33.

18. Панкрац Ю.Д. Пропозициональная форма представления знаний // Язык и структуры представления знаний. М., 1992. С. 78-97.

19. Fodor J. Psychosemantics: The Problem of Meaning in the Philosophy of Mind. Cambridge, Massachusetts: MIT Press, 1987.

20. Sornicola R., Brown K., Miller J. Elsevier. Concise Encyclopedia Of Grammatical Categories. Amsterdam; Tokyo, 1999. 508 p.

21. Чейф У. Данное, контрастивность, определенность, подлежащее, топики и точки зрения // Новое в зарубежной лингвистике. Вып. 11: Современные синтаксические теории в американской лингвистике. М., 1982. С. 310-337. 
22. Арутюнова Н.Д. Предложение и его смысл. М., 1976. 383 с.

23. Энциклопедический словарь «Святая Русь». URL: http://www.sovslov.ru/tolk/lojyt.html (дата обращения: 25.04.2016).

FUNCTIONAL SPECIFICITY OF RUSSIAN NOMINAL DERIVATIVES REFERRING TO A
SYNCRETIC ZONE OF THE RUSSIAN LANGUAGE WORD-BUILDING SYSTEM Vestnik Tomskogo gosudarstvennogo universiteta. Filologiya - Tomsk State University Journal of Philology. 2016. 6 (44). 50-67. DOI: 10.17223/19986645/44/4

Olga V. Nagel, Tomsk State University (Tomsk, Russian Federation). E-mail: olga.nagel2012@yandex.ru

Keywords: syncretic derivatives, proposition, textual inclusion, focus, topic, proposition realization.

The study reveals the functional specificity of Russian nominal derivatives referring to a syncretic semantic zone of the Russian language word-building system. Syncretic derivatives are characterized by a composite semantic structure comprising characterizing and evaluating components. The research is grounded on functional and cognitive methodology which focuses on the study of a derivational model, propositional structure of its derivatives and realization of this structure in utterances. Using resources of the Russian National Corpus the nature of syncretic derivatives functioning is being analyzed and correlated with a dynamic propositional structure of the derivatives. Analyzing contexts where Russian syncretic derivatives function either in a syntactic position of a focus or a topic the author studies coordination of derivatives propositional elements and sentence propositional elements in the utterance and states basic laws of a derivative text inclusion. It is claimed that the coordination of propositional structures is supported by semantic parallelism of language units (preceding and following a derivative) and components of a derivative propositional structure (S, P, M1, M2, M3). The analysis proves flexibility of the derivatives referring to the Russian language syncretic derivational zone in conveying different aspects of characterization and evaluation. The stated flexibility allows a speaker to manipulate text inclusion of a syncretic derivative focusing on the explication of different components of a derivative propositional structure.

Employing translation as an instrument for linguistic analysis the author reveals typological differences in Russian and English word-building patterns used to create and apply characterizing derivatives. The main difference revealed while analyzing Russian translations of English sentences is the dominance of syncretic derivatives in Russian when it comes to simultaneous characterization and evaluation (including speaker's personal attitude to a person) of a person in Russian. Russian syncretic derivatives are not only used by a translator to convey the meaning of English derivatives but also serve as equivalents for different predicative units of the English language. The results show the polyfunctional nature of Russian syncretic derivatives due to their poly-propositional structure while English nominal word-building patterns create more mono-functional derivatives used either for characterization or evaluation.

\section{References}

1. Rezanova, Z.I. (1996) Funktsional'nyy aspekt slovoobrazovaniya. Russkoe proizvodnoe imya [Functional aspect of word-building. Russian derivational name]. Tomsk: Tomsk State University.

2. Rezanova, Z.I. (2005) Imennaya deminutivnaya derivatsiya $v$ mekhanizmakh vyrazheniya otsenki [Nominal diminutive derivation in the mechanisms of evaluation explication]. In: Rezanova, Z.I. (ed.) Kartiny russkogo mira: Aksiologiya v yazyke i tekste [Images of the Russian world. Axiology in language and text]. Tomsk: Tomsk State University.

3. Nagel', O.V. (2005) Russkie imennye slovoobrazovatel'nye tipy sinkretichnoy semantiki (funktsional'no-kognitivnyy aspekt) [Russian nominal word-building types of syncretic semantics (functional and cognitive perspective)]. Philology Cand. Diss. Tomsk.

4. Nagel', O.V. (2014) Semantics of a derivative name as an activator of Russian speaker metalinguistic cognition. Vestnik Tomskogo gosudarstvennogo universiteta. Filologiya - Tomsk State University Journal of Philology. 2 (28). pp. 63-71. (In Russian).

5. Slovarius. (2016) Tolkovyy slovar' Ozhegova [Dictionary of the Russian Language by Ozhegov]. [Online] Available from: http://slovarius.com/page/govorun.php. (Accessed: 15th March 2016).

6. Slovariya.ru. (2016) Tolkovyy slovar' russkogo yazyka pod red. D. N. Ushakova [Ushakov's 
Explanatory Dictionary of the Russian Language]. [Online] Available from: http:// slovariya.ru/rus/sa/govorun. (Accessed: 15th March 2016).

7. Kubryakova, E.S. (2004) Yazyk i znanie: Na puti polucheniya znaniy o yazyke: Chasti rechi s kognitivnoy tochki zreniya. Rol' yazyka v poznanii mira [Language and knowledge: On the way of learning the language: Parts of speech from a cognitive point of view. The role of language in the cognition of the world]. Moscow: Yazyki slavyanskoy kul'tury.

8. Russian National Corpus. (2015). [Online] Available from: http://www.ruscorpora.ru. (Accessed: 15th March 2016).

9. Nagel', O.V. (2015) Derivation Peculiarities of Nominal Nouns in Slavic Languages (Based on the Parallel Subcorpus of the National Russian Corpus). Rusin. 3 (41). pp. 226-240. (In Russian). DOI: $10.17223 / 18572685 / 41 / 16$

10. Rezanova, Z.I. \& Shilyaev, K.S. (2015) Russian National Corpus in teaching the use of russian diminutives. Mezhdunarodnyy zhurnal prikladnykh i fundamental'nykh issledovaniy. 5-4. pp. 634-663. (In Russian).

11. Araeva, L.A. (2009) Slovoobrazovatel'nyy tip [Word-building type]. Moscow: URSS.

12. Yantsenetskaya, M.N. (2014) The propositional aspect of word formation (the overview of works by Siberian scholars). Vestnik Tomskogo gosudarstvennogo universiteta. Filologiya - Tomsk State University Journal of Philology. 1 (27). pp. 167-192. (In Russian).

13. Langacker, R. (1991) Foundations of Cognitive Grammar. Vol. 2. Stanford: Stanford University Press.

14. Chomsky, N. (1991) Linguistics and cognitive science: problems and mysteries. In: Kasher, A. (ed.) The Chomskyan Turn: Generative linguistics, philosophy, mathematics, and psychology. Oxford: Blackwell. Press.

15. Croft, W. \& Cruse, D.A. (2004) Cognitive linguistics. Cambridge: Cambridge University

16. Talmy, L. (2000) Towards a cognitive semantics. Vols 1-2. Cambridge, MA: MIT Press.

17. Dem'yankov, V.Z. (1994) Kognitivnaya lingvistika kak raznovidnost' interpretiruyushchego podkhoda [Cognitive linguistics as a type of interpretational approach]. Voprosy yazykoznaniya. 4. pp. 17-33.

18. Pankrats, Yu.D. (1992) Propozitsional'naya forma predstavleniya znaniy [Propositional way of knowledge representation]. In: Berezin, F.M. (ed.) Yazyk $i$ struktury predstavleniya znaniy [Language and knowledge representation structures]. Moscow: RAS.

19. Fodor, J. (1987) Psychosemantics: The Problem of Meaning in the Philosophy of Mind. Cambridge, MA: MIT Press.

20. Brown, K. \& Miller, J. (eds) (1999) Concise Encyclopedia of Grammatical Categories. Amsterdam; Tokyo: Pergamon.

21. Chafe, W. (1982) Dannoe, kontrastivnost', opredelennost', podlezhashchee, topiki i tochki zreniya [Givenness, Contrastiveness, Definiteness, Subjects, Topics and Point of View]. Translated from English. Novoe v zarubezhnoy lingvistike. 11. pp. 310-337.

22. Arutyunova, N.D. (1976) Predlozhenie i ego smysl [Sentence and its sense]. Moscow: Nauka.

23. Sovslov.ru (n.d.) Entsiklopedicheskiy slovar' "Svyataya Rus"” [Encyclopedic dictionary "Holy Rus"]. [Online] Available from: http://www.sovslov.ru/tolk/lojyt.html. (Accessed: 25th April 2016). 